\title{
REMEDIATION AND TREATMENT OF DIOXIN CONTAMINATION: A FORMER SAWMILL SITE WITH SOIL AND SEDIMENTS CONTAMINATED WITH DIOXIN AND PENTACHLOROPHENOL HAVE BEEN REMEDIATED USING EXCAVATION METHODS, AND THE MOST DIOXINE IMPACTED SOIL HAVE BEEN SUCCESSFULLY TREATED WITH CHEMICAL OXIDATION
}

HELENA NORD

RGS 90 SVERIGE AB

\begin{abstract}
Between 1928 and 1976, a sawmill was located at the shore of Brosjön in the small village of Ydrefors in Ydre municipality in eastern Sweden. During the last ten years of the sawmill's operating years, a product namned Servarex was used to prevent fungus attacks of the timber. Servarex caused a contamination of dioxins in the soil, as well as pentachlorophenol (PCP) in groundwater. In the main study, the sampling revealed concentrations of dioxins $(610,000$ $\mathrm{ng} / \mathrm{kg}$ ) that was the highest detected level in Sweden. During the autumn of 2013, RGS 90 performed remediation of dioxins contaminated soil and sediment through excavation. The dioxins contaminated soil with levels above the hazardous waste limit $(15,000 \mathrm{ng} / \mathrm{kg})$ is not allowed to be deposed in Sweden. The soil was therefore successfully treated with chemical oxidation at RGS 90:s facility in Norrköping, Sweden.
\end{abstract}

\section{KEYWORDS}

Soil remediation; Dioxine treatment; Sawmill; Excavation.

\section{INTRODUCTION}

Dioxins are a group of compounds which are very toxic and can cause e.g. cancer, immune deficiencies and reproductive changes. They have a low solubility and adsorbs very hard to organic matter. Also, they are highly persistent in nature and bioaccumulative. Dioxins are usually known to associate with saw mills, pulp and paper mills as well as organochlorine pesticides productions.

The Swedish limit for hazardous waste concerning dioxin is $15,000 \mathrm{ng} / \mathrm{kg}$. Soil containing contamination levels above the hazardous waste limit must be treated in order to irreversibly destroy the long lived pollutants, as stated in the regulations of the POP convention. Within Sweden, the way of achieving this has been through thermal treatment. Thermal treatment, 
however, has the down-sides in being located to one single facility often resulting long transports and being a very energy consuming and expensive treatment ( $400 € /$ ton $)$.

\section{THE YDREFORS SITE}

Between 1928 and 1976, a saw mill was located at the shore of Brosjön in the small village of Ydrefors in Ydre municipality in eastern Sweden. During the last ten years of the saw mill's operating years, a product namned Servarex was used to prevent fungus attacks of the timber. Servarex caused a contamination of dioxins in the soil, as well as pentachlorophenol (PCP). In the main study, the sampling revealed concentrations of dioxin $(610,000 \mathrm{ng} / \mathrm{kg})$ that was the highest detected levels in Sweden.

During the autumn if 2013, RGS 90, performed excavation of the dioxin contaminated soil as well as the dioxin contaminated sediments along the shore of Brosjön. In total, about 5,000 tons were excavated where about $10 \%$ were estimated to contain dioxin levels above 15,000 $\mathrm{ng} / \mathrm{kg}$. This soil was transported to RGS 90's facility in Norrköping where RGS 90 are developing a new technique for treatment of dioxin contaminated soils with chemical oxidation.

\section{THE TREATMENT TECHNIQUE}

Chemical oxidation can be performed in several different ways where two of them are Fenton's reagent and base activated persulphate. These two are the main technique that RGS 90 has used to remediate the dioxins.

There are also other techniques that have been proved to be able to remediate dioxins, as an example, zero-valent iron (ZVI) can be named. Micro and nano sized ZVI has been shown to degrade dioxins, although very slow. However, when the ZVI became palladized the reaction was 3-4 times faster [2]. Also, there has been shown that dioxins are possible to treat through milling with calcium oxide [3]. Furthermore, there has been shown that it is possible to extract dioxins from soil using $90^{\circ} \mathrm{C}$ water and that it is possible to oxidize dioxins with UV light combined with an photometric catalyst (titanium oxide) [4].

Fenton's reagent is based upon the reaction of hydrogen peroxide which is capable of oxidizing dioxins. The hydrogen peroxide is usually iron activated to form hydrogen radicals and hydroxyls that provides an extremely quick oxidative reaction. Persulfate generates sulphate radicals when activated by a base. The radicals then provides an oxidation similar to the one provided by Fenton's reagent.

A $99 \%$ reduction of dioxins has been shown to be oxidized using three treatments of Fenton's reagent [1]. However, the trial was performed at a bench scale, which does not meet the same challenges as a large scale trial. Some of the issues of a large scale trial includes that the extremely fast reaction of Fenton's reagent which causes difficulties dispersing Fenton's reagent in the soil, as well as the explosive risk of concentrated oxygen from hydrogen peroxide and the working hazards for the personnel performing the treatment.

RGS 90 has, through performing a controlled treatment with Fenton's reagent and persulphate been able to reduce the dioxin levels in a sandy soil by $27-55 \%$ and thereby lowering the dioxin levels to beneath the level of required treatment. The treatment can be repeated if the remediation goal is not achieved at the first attempt, with an estimated treatment cost of $1 / 3$ of 
thermal treatment. This treatment can be used at any facility with the proper permissions, thereby drastically reducing the transport costs.

\section{CONCLUSIONS}

In comparison to the common technique used today for treating dioxins (thermal treatment) dioxins can also be treated by Fenton's reagent as well as persulphate. These treatments provide a much smaller cost than thermal treatment and also are not restricted to a single location in Sweden.

\section{REFERENCES}

[1] Kao, CM., Wu, MJ., 2000. Enhanced TCDD degradation by Fenton's reagent peroxidation. Journal of Hazardous Materials, B74, 197-211.

[2] Kim, JH., Tratnyek, PG., Chang YS., 2008. Rapid dechlorination of polychlorinated dibenzo-p-dioxins by bimetallic and nanosized zerovalent iron. Environmental Science and Technology, 42(11), 4106-12.

[3] Namura, Y., Nakai, S., Hosomi, M., 2005. Elucidation of degradation mechanism of dioxins during mechanochemical treatment. 39(10):3799-804.

[4] Strandberg, J., Odén, H., Maynard Nieto, R., Björk, A., 2001. Treatment of dioxin contaminated soils. Literature Review and Remediation Method Development. B1993. IVL, Swedish Environmental Research Institute. 